\title{
The Role of Repetition in the Rise of Concessivity
}

\author{
Haritini Kallergi \\ Aristotle University of Thessaloniki \\ hkallerg@enl.auth.gr
}

\section{Abstract}

The paper deals with three types of lexical repetition that are involved in structures of asyndetic clause linkage with a concessive meaning. The central question is: how do these apparently similar but also different patterns come to have concessive interpretations? An attempt to answer this question is made on the following basis: the structures involving lexical repetition are treated as a group of constructions (in the Fillmorean sense of the term) and analyzed as the products of a process of development (whether diachronic or synchronic) towards concessivity. With respect to this process, the meanings and functions of repetition, as well as various scenarios of pragmatic enrichment of these meanings play a significant role.

\section{Preliminaries}

The following examples, which may be found in oral, colloquial speech of Modern Greek (MG) ${ }^{1}$, seem to invite concessive readings of the type although $p>q$ :
(1) grinazes
minazes, to fajes
olo sto telos
nag-3.IPFV.PST [echo] it eat-3.SG.PFV.PST all in-the end
"you were nagging and all, but you ate it all in the end"

\begin{abstract}
1 The data were collected either from the spontaneous speech of speakers of Northern Greek dialects of Modern Greek or from Google searches (especially in informal blogs). In the latter case, it is not easy to retrieve information about the dialect of the speakers, whose utterances have been used. Regarding example (1) (echo-reduplication), Konstantinidou (2004: 346) reports that it is a dialectal feature of people living in settlements or neighbourhoods of Thessaloniki, made by refugees from Asia Minor and the Pontus (e.g. Brusa, Ionia). For the other two constructions (examples 2 and 3), there is no available information on origin, as they are typically not referred to as such in the literature.
\end{abstract}

\section{(cc) BY-NC-ND}


(2) grinazes ksegrinazes, to fajes sto telos nag-3.IPFV.PST kse-nag-3.IPFV.PST it eat-3.SG.PFV.PST all in-the end "despite your nagging, you ate it all in the end"

(3) grinazes grinazes, to fajes olo sto telos nag-3.IPFV.PST nag-3.IPFV.PST it eat-3.SG.PFV.PST all in-the end "you were nagging and nagging, but you ate it all in the end"

As is evident, all three examples above involve lexical repetition: in example (3), the repetition of the verb is exact, whereas in (1) and (2) the second occurrence of the verb is somewhat changed. In fact, the repetition of example (1) has been observed in other languages and has often been discussed under the terms "echo reduplication" or "echo-construction" (see, e.g., Keane 2005; Stolz 2008; Kirchner 2010). Repetition of example (2), on the other hand, seems to be a case specially encountered in MG and involves suffixation of the second word by the prefix kse(for the semantics of kse-, see, e.g., Efthymiou 2001, 2002).

Despite their differences with respect to the formal properties of lexical repetition, the three examples above exhibit a number of similarities with respect to their concessive reading.

First, they all have a concessive interpretation without the involvement of a concessive marker. In fact, they express concessivity, in fulfilling the following basic requirements: they involve a relation between two propositions ( $p$ and $q$ ), which may be said to co-occur and to be incompatible with each other, on the basis of world knowledge (Halliday \& Hasan 1976; König 1988). This relation is signaled by the juxtaposition of the repeated items (that designate proposition p) to another clause (that designates proposition q), without the mediation of an item that explicitly marks this relation as concessive. Note that a concessive marker may appear in cases (2) and (3) above. For example:

(4) (Molonoti) grinazes grinazes/ ksegrinazes, to fajes olo sto telos "(although) you nagged and nagged, you ate it all in the end"

However, its presence is not necessary. In the case of echo-construction (case 3 above), adding a concessive marker is rather inappropriate:

(5) ?(Molonoti) grinazes minazes, to fajes olo sto telos.

Second, in all three cases the lexical repetition is necessary in order for the concessive reading to arise. That is, instances like those in (6) are impossible.

(6) "Grinazes/"minazes/"ksegrinazes, to fajes olo sto telos "you nagged/you nagged [echo]/you kse-nagged, you ate it all in the end" 
Third, in the majority of the cases above, the repetition is bound to sentenceinitial position (similarly to other concessive constructions, see, e.g., Nikiforidou 1990). Thus, with the exception of repetition with kse-, reversing the order of clauses is unacceptable:

(7) *To fajes olo, grinazes grinazes/ minazes

"you ate it all, you nagged and nagged / you nagged [echo]"

but

(8) To fajes olo, grinazes ksegrinazes.

"you ate it all, despite your nagging (you nagged kse-nagged)"

Fourth, although all three cases of repetition have a range of other functions in $M G$, they are all subject to special restrictions when they have a concessive interpretation. For example, a word may be repeated three or more times, when the repetition stands in a causal relationship with a juxtaposed clause, as in (9):

(9) xartça, xartça, xartça, piksame sto xartomani

lit. 'papers, papers, papers we got stuck in the paper-pile'

"with all these papers, we got stuffed in paper".

However, repetition in a concessive relation with the subsequent clause is restricted to two instances:

(10) xartça, xartça, ?xartça, aðji ine i kaði anaciklosis 'papers, papers, ?papers, empty be-3.PL the bins recycling-GEN' "despite (having) all these papers, the recycling bins are empty".

Also, when all three types of repetition express contempt/rejection, the conjunction ce 'and' may interfere between the repeated words (examples 1113), whereas this is not possible when these types of repetition are involved in concessive relations (example 14):

(11) Papás ce papas, mas eprikses!

lit. 'priest and priest you swelled us'

"(you tell us he is a) priest all the time, you got us tired!"

(12) Ti papás ce ksepapás, oli ta iðja ine.

lit. 'what priest and kse-priest they are all the same'

"you may say he is a priest, but they are all the same"; 
(13) Ti Kundera ce Mundera mu tsabunas!

'what Kundera and [echo] me talk.about-2.SG.PR'

"Kundera schmundera! What are you talking to me about?"

but

(14) ?Grinaze ce grinaze/minaze/ksegrinaze, to faje olo.

's/he nagged and nagged/echo/kse-nagged, he ate it all'

"although s/he nagged, she ate it all."

Finally, the three types of repetition are characterized by special intonation when juxtaposed to a clause in a concessive relation. Specifically, they are accompanied by a continuation rise, whereas some constituent of the clause that follows carries narrow focus (e.g., grinakse, grinakse, to faje OLO sto telos). It appears that the particular melody characterizes all examples from (1) to (3) above and contributes significantly to their concessive meaning².

\section{Constructions}

In view of the characteristics and restrictions discussed above, the three cases of juxtaposition that involve lexical repetition can be treated as constructions, in the specific sense of Construction Grammar of Fillmore et al. (1988). Fillmore et al. 1988: 501, 502) define the construction as a pair of syntactic-semantic rules that gives direct pragmatic interpretation, i.e. without the mediation of the proposition expressed by the structure. In "trespassing" semantics to have a direct pragmatic interpretation, constructions à la Fillmore et al. are idioms in a very broad sense. Such idioms may extend beyond the phrase and often consist of a "skeletal" structure that may be filled by a large number of lexical items.

Our cases of juxtaposition of a repetitive structure to a clause ( $X X / X \mathrm{kse}-X$ I $X[m] X, Y)$ may be considered concessive constructions because: i) they are instances of a specific meaning attached to a specific form, i.e. a pairing of a skeletal form such as the above with a concessive meaning (remember the non-

2 Note that this melody is not unique to these cases of concessive relation, but it may accompany other concessive constructions of the type 'although $X, Y^{\prime}$ (e.g. concessive constructions with na, see Nikiforidou 1990: 210). Also, the intonation pattern in question may characterize causal constructions (for more on the intonation of repetition in causerelation utterances in technical terms, see Kallergi 2013). It is rather claimed here that in our cases, the repetition needs this intonation to be interpreted as the protasis of the clause that follows (the apodosis). 
necessary presence of a concessive marker), ii) they are idiosyncratic, in that they are not strictly predictable from the semantics of repetition and the clause that follows. They are also language-specific (e.g. they are not present in English); iii) the "skeletons" in question have open lexical slots. In particular, $X$ may be filled by almost any verb, noun or adjective"; and iv) they have special formal features, such as distinctive intonation (see also Taylor 2002 for phonological features of constructions). Also, in accordance to Nikiforidou's (1990) treatment of $X, Y$ structures (where $X$ a clause introduced by $n a$ ) as constructions in the above sense, an additional criterion is that the structures involving repetition do not have a concessive reading outside the specific $X, Y$ configurations.

A legitimate question might now be: how do structures like $X X, Y$ or $X$ kse- $X$, $Y$ come about as concessive constructions? Already by assuming that they are constructions (viz. types of formal idioms), we suggest that they have probably undergone some process through which they have acquired their special characteristics. Fillmore et al. (1988: 534) assume that constructions arise from syntax. But this might not explain much in our case, since in the structures in question we are faced with juxtaposition, i.e. with a very primitive form of syntax. Yet, even if the various types of repetition that we examine are juxtaposed to some clause, they have independent semantics, in which we may seek for the "seeds" of concessive relations (taking into account the semantics of the clause that follows and general principles of interpreting the order of clauses, e.g. iconicity, see Haiman 1986).

In arguing for grammar as "emergent", Hopper (1987) suggests that constructions arise, in fact, through language use. Through use, chunks of language become "structuralized", in that they gradually achieve "cross-textual

3 However, constructions involving the morphological alteration of the initial consonant as in the $X-[m] X$ construction (encountered as echo-word formation, distortive reduplication etc., Stolz 2008; Konstantinidou 2004) are found in a wide range of languages, mostly of Eastern Europe and Asia. Note, however, that it is not certain whether in these languages this kind of formation is involved in concessive constructions (rather than simply meaning " $X$ and the like", see Keane 2005). Also, in English, a parallel construction with concessive readings would involve the so-called schm-reduplication: fat-schmat, as long as she's happy (Stolz 2008: 115). Again, the sentence as a whole can be marginally considered as expressing a concessive relation (instead, the first part means "Who cares if she's fat?" see, e.g. Zwicky \& Pullum 1987). Regarding the concessive readings of simple reduplication/repetition, I know only one example in the literature: Riau Indonesian kecil kecil punya cewek itu 'small small have girl this' "even though he's small, he's got girlfriends" (Gil 2005: 57).

4 Some examples with nouns and adjectives are: krisi ksekrisi/krisi misi, oli ekso ine 'crisis kse-crisis/ crisis [echo] everybody out be-3.PL' "despite the (economic) crisis, everybody goes out"; arostos ksearostos, $\theta$ a pao 'ill kse-ill will go-1.SG.PFV' "even if I'm ill, I'll go". Admittedly, the echo-construction is less flexible with large classes of items (whether verbs, nouns or adjectives) and it is also restricted phonologically, since words beginning with a vowel or /m/ are dispreferred as bases (see also Keane 2005; Stolz 2008). 
consistency" (ibid: 150), i.e. a kind of productivity. Specifically with respect to concessive markers, König (1988) takes a "combining" position in suggesting that "the development of a genuine concessive meaning and its differentiation from related meanings is motivated by general principles of language use and interpretive augmentation". In other words, a concessive construction may be rooted both in the other meanings that the form of the construction may have, as well as in language use. Note that the latter is not restricted to earlier language use, i.e. in the use of the structures in a diachronic perspective. As Hopper 8 Traugott (1993: 169) argue, "combining clauses in grammatical ways is grounded in rhetorical production strategies" (emphasis mine). This means that the concessive constructions under examination may be cases of clause combining (without having acquired complete grammatical status), which occur in everyday discourse and on a synchronic basis (for types of clause linkage in general and on a cross-linguistic basis, see, e.g. Cristofaro 2003).

In the next two sections, we will examine in some more detail the aforementioned assumptions on the evolution of the concessive constructions in question.

\section{Semantics of Repetition and the Evolution of Concessive Constructions}

In the previous section, it was suggested that the "seeds" of the concessive meaning of the constructions in question may be sought in other meanings that these forms have. In this section, we will examine the semantics of the three types of repetition and briefly discuss the various possibilities that this semantics give for the rise of concessivity.

It is important to mention here that, cross-linguistically, certain semantic domains concerning the proposition $p$ have been attested as sources for the rise of concessive meanings in grammaticalization. König (1988) discusses the origin of concessive markers in notions such as contempt, conditionality (i.e. conditional clauses as predecessors of concessive clauses), "free choice quantification" (viz. the meanings of 'all', 'whatever' etc.), and the emphatic assertion of the truth of $p$. The latter two notions relate to epistemic necessity and the notion of "totality of possible worlds", which have also been discussed as sources of concessive markers (see van der Auwera \& Plungian 1998 for concessive grams out of modal markers, Sidiropoulou 1990 for emphatic assertion or epistemic necessity as paths from causation to concession, and Veloudis 1997 for the connection of MG concessive markers with words that denote totality).

Let us now examine whether these notions are present in the types of repetition that we are dealing with. 


\subsection{X [m]X Repetition}

This type of repetition (also known as echo-reduplication) has been discussed by Daniel $\&$ Moravcsik (2005) as a device for the expression of associative plural, i.e. the meaning of ' $X$ the like'. In this sense, the second constituent rather vaguely encloses all the entities associated to $X$, which may be dismissed as irrelevant for the current purposes of the speaker. Thus, it is fairly easy for ' $X$ and the like' to also mean ' $X$ and whatever else relevant' (i.e. free choice quantification). Moreover, it is easy to consider what is not overtly mentioned as unimportant and, in this sense, to use the construction in order to express contempt, as has been observed in various languages, including MG (Konstantinidou 2004, Keane 2005, Stolz 2008). In fact, Stolz (2008: 126-127) argues that the incomplete morphophonological copying of $X$ in the second constituent metaphorically implies that whatever is referred to by $[\mathrm{m}] X$ is a "bad copy" of $X$, which does not deserve to be mentioned. By means of $[\mathrm{m}] X, X$ may also be mocked.

In section 4, we will see how the notions of free choice quantification and contempt may encourage the concessive reading of this construction.

\subsection{X kse-X Repetition}

The prefix kse-primarily signals removal of meaning and cancellation (Efthymiou 2001, 2002), in the sense of Eng. un- or de- (e.g. kse-yrafo 'un-write-1.SG.PR' "delete, erase from a list", kse-pupuאazo 'un-feather-1.SG.PR' "pluck"). In this sense, also, a large amount of derivatives with kse- denote the opposite (or reverse) meaning from the meaning of their base: payono 'freeze' - kse-payono'un-freeze' "defreeze"; dino 'dress'- kse-dino 'un-dress' "undress".

In a metaphorical extension, removal and cancellation may concern the value of $X$, especially when its replica carrying kse-immediately follows it. In this way, kse-X becomes, as with echo-reduplication, a way for the speaker to derate $X$. This idea is supported by the fact that, in this function, kse-is extremely productive and forms words that do not exist independently in MG, nor can they stand alone (i.e. without being juxtaposed to X): papas ksepapas "priest or whatever", krio ksekrio "cold or whatever" but "ksepapas 'kse-priest', "ksekrio 'kse-cold'. Furthermore, the use of kse-is strictly colloquial as it is prone to sound offensive or pejorative.

More importantly, however, the creation of opposites by means of derivational kse- may be extended in its productive use. Cases like ksepapas and ksekrio may be conceived as virtual opposites of papas and krio respectively. The juxtaposition of opposites in papas ksepapas and krio ksekrio creates a situation, whereby the totality of possible worlds is covered (see Sidiropoulou 1990; Veloudis 1997, 2005). By taking into account the two extreme possibilities (say, of cold and "non-cold") the speaker exhausts a whole area of possibilities (the totality of possible worlds). In other words, $X$ kse- $\$ X involves the semantic ingredients of epistemic necessity. 


\section{3. $X($,$) \times Repetition$}

Word repetition has a very wide range of functions, in some of which we can identify sources of concessivity. One such function is emphasis (see, e.g. KakridiFerrari 1998 for MG). By placing emphasis, as, e.g., in Erçete! Erçete! "S/he's coming! S/he's coming!", the speaker asserts the truth of the proposition, and this semantically relates to epistemic necessity.

Second, and as we have already mentioned in section 1, repetition may be used to signal contempt and it may also express irony or indignation about something said (usually, continuously) by another interlocutor or referent in the context:

(15) Aman! Siynomi, siznomi, oli tin ora, mas kurasan!

'INTER] sorry sorry all the time us tire-3.SG.PFV.PST'

"Well, enough! By saying they're sorry all the time, they got us tired!"

Also, similarly to echo-reduplication (although much rarely, and certainly not in MG), repetition or reduplication may express the associative plural, as in Thai: non non 'money and that sort of thing' (Moravscik 1978). In fact, this function of quantification is mentioned under the term "similarity" by Moravscik, but it appears to be strikingly similar to the function of echo-reduplication that encourages connotations of contempt and dismissiveness on the part of the speaker.

Finally, repetition, especially of verbs, often denotes iterativity or continuation (see Kakridi-Ferrari 1998; Kallergi (2013) and references therein). In juxtaposition to another clause, this type of repetition is often employed to signal a causal or conditional relationship to the proposition of that clause. For instance:

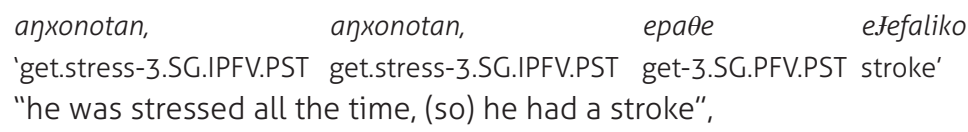

In (16), (continuous) stress is interpreted as the cause of the stroke. Also, with verbs in the imperative, as in leje leje, $\theta$ a ton pisis 'say-2.SG.IMP say-2.SG.IMP will him convince-2.SG.IPFV" "by telling him (something) all the time, you will convince him", repetition is semantically equivalent to a conditional ("if you tell him something all the time, you will convince him") $)^{5}$.

5 In Kallergi (2013), I argue that both such instances of repetition may be regarded as cases of total reduplication that express the iterative (or durative, see Stolz et al. 2011) and that especially reduplicated verbs in the imperative may possibly be viewed as functionally equivalent to MG "gerunds" or "converbs", which also have conditional readings (see, e.g., Tsimpli 2000; Moser 2001). 
In the next section, we will attempt to explain how these meanings can be pragmatically exploited to render the concessive reading of the constructions under study. For the relation of causality, conditionality and concessivity, the reader may also see, e.g., Sidiropoulou (1990), Athanasiadou (1997), CouperKuhlen \& Kortmann (2000) and Kitis (2002).

\section{Pragmatics and the Evolution of Concessive Constructions}

Having examined the functions and meanings of the types of repetition in question, we may now see whether these give rise to the concessive reading of our constructions and, if so, how. It turns out, however, that the various scenarios of pragmatic enrichment towards concessivity may work independently of or in parallel with the meanings mentioned in section 3.

There are two (interestingly, opposite) scenarios of pragmatic enrichment that are based on some of the meanings we have seen to be associated with repetition.

A highly plausible scenario involves the pragmatic "strengthening" of the proposition in $p$. The meanings/functions of epistemic necessity ('whether $X$ or not'), free choice quantification ('any kind of $X^{\prime}$ ) and the emphatic assertion of the truth of $p$ ('it is certainly the case that $X$ ') reinforce the truth conditions under which the proposition in $p$ holds. Given that the premises of $q$ (viz., $p$ ) become very strong and that $q$ is incompatible with $p$ but also true, $q$ is interpreted to occur despite $p$ (see also Veloudis 1997 for a similar analysis).

Strengthening of $p$ may also work at the level of implicatures. As König (1988: 162) argues, "there is no point in emphasizing the truth of the 'antecedent' proposition unless the truth or the significance of this proposition as an argument is somehow called into question". Through the violation of the principle of Relevance (Grice's "R principle", viz. 'say no more than you must'), the addressee understands that the speaker's reinforcing of $p$ (which is already known to be true) prepares the ground for $q$ as the competitor of $p$.

This mechanism of strengthening works similarly to the 'yes, but...' moves in dialogues. In other words, it is important for this scenario that the first part of the concessive relation "acknowledges" the truth of $p$, against which the truth of $q$ is presented (Sperber \& Wilson 1995, Couper-Kuhlen \& Thompson 2000). To this end, repetition plays an important role, whether it occurs across speakers or within the utterance of the same speaker. Repetition as a direct quotation (an "echo") of an interlocutor's statement ( $A: X, B: X$, but $Y$ ) or as a mocking representation of a previous statement (as in example 15 above) sets the background for an evaluation (Sperber \& Wilson 1995) or an attack (Couper-Kuhlen \& Thompson 2000). In this vein, Couper-Kuhlen \& Thompson 
(2000) argue that concession develops according to the following rhetorical ${ }^{6}$ pattern:

(17) The "Cardinal Concessive" (adapted from Couper-Kuhlen \& Thompson 2000: 382)

$1^{\text {st }}$ move (stating)>
$2^{\text {nd }}$ move (conceding)>
$3^{\text {rd }}$ move (countering)>
A: $\boldsymbol{X}$ (A states something)

$B: \boldsymbol{X}^{\prime}$ (B acknowledges validity of A's statement)

$B: Y$ (B goes on to claim the validity of a potentially contrasting statement or point)

Couper-Kuhlen \& Thompson additionally suggest that speaker B introduces his/her contrasting statement by means of "implicative prosody" and "semantic partitioning" (2000: 381). The former roughly refers to the intonation of repetition mentioned in section 1 : the continuation rise (here concerning $X^{\prime}$ ) "implies" that new, interesting information is coming. The latter refers to the fact that, by making an acknowledgement, speaker B has the opportunity to set up a direct semantic contrast between an element of $X$ and an element of $Y$.

Semantic partitioning is even more strongly evident in a relevant scenario of pragmatic enrichment towards concessivity, the "falsified expectations" scenario. In this scenario, the starting point is the meaning of iterativity and its connotations of causality and conditionality, which were mentioned with respect to repetition in section 3. To illustrate, let us take example (16) above: apxonotan, anxonotan, epäe efefaliko "he got stressed all the time, (so) he had a stroke". As has been mentioned before, on the basis of Relevance as well as world knowledge, the hearer infers a cause-effect relationship between the iteration of the event in $X$ ('he got stressed') and the event in Y ('he had a stroke'). However, if instead of epäe efefaliko, Y involves a proposition like telia errapse 'perfectly write-3.SG.PFV.PST' "he got on perfectly with his exams", the expectation about the cause-effect relationship is falsified due to the semantic contrast between 'he got stressed' and '(he got on) perfectly' (which is additionally reinforced by narrow focus on $t^{2}\left(i a^{7}\right.$ ). In assuming that the speaker is still being relevant, and that both $X$ and $Y$ are true, the hearer interprets the relation between the two as concessive (or as "anti-causal", according to an alternative label for the concessive, see Latos 2009 and Rudolph 1996: 48-52).

6 In fact, Couper-Kuhlen \& Thompson (2000: 383) mention that conceding as discourse/ textual relation and especially of this type (by first acknowledging the opposite view) has "been a concern of rhetoricians" as an optimal way to counter and persuade.

7 The truth of this contrastive proposition (that s/he did well with his/her exams) has to be emphasized for the contrast to be sustainable. Thus, apart from narrow focus intonation, telia is preposed (it comes before the verb), whereas with the default (and more "neutral") word order (eyrapse telia), emphatic stress would perhaps not be adequate for the concessive effect. 
The alternative scenario to strengthening $p$ (and the mechanisms we discussed so far), is to derate $p$. Put in better terms, the speaker may undermine the capability of $p$ to resist or defy the truth of $q$. This can be done by presenting $p$ as weak or irrelevant. The notion of contempt and rejection which has been referred to in respect to repetition (especially of the $X[\mathrm{~m}] X$ and $X k s e-X$ types) may be exploited as a strategy to reject $p$ as a strong competitor of $q$ and to present $q$ as true in any case. König (1988: 157) suggests that the notion of contempt directly relates to notions of dissonance and conflict, without further discussing this relation. Halliday \& Hasan (1976: 254) also mention the notion of irrelevance (premises that are irrelevant and, thus, cannot affect $q$ ) in their discussion of the meaning of "dismissal" and its importance in "adversative (concessive) relations" (parenthesis mine). Extending this connection a bit further, we may assume that the meaning of contempt (interestingly attested with all types of repetition under study), may "ignite" the concessive reading of the constructions in question, even if it is only pragmatically exploited in order for the speaker to dismiss $p$ as irrelevant to the truth of $q$ (' $q$ is true no matter what you have in $p>$ despite $p^{\prime}$ ).

\section{Conclusion and Issues for Future Research}

This brief study has shown that formal repetition seems to play a significant role in the rise of concessivity. Via the meanings of the three types of repetition under examination (simple repetition, echo-reduplication and repetition with kse-suffixation), and especially the meanings of emphasis, iterativity (> causality, conditionality) and contempt, repetition was seen to relate to: i) the semantics that stand as synchronic sources for the rise of forms with concessive meanings (and which may largely coincide with the diachronic sources of concessive markers in the literature), and ii) the discourse strategies from which concessive interpretations may arise synchronically.

Moreover, by treating such forms as constructions (as in Fillmore et al. 1988), we have, on the one hand, isolated the three cases of interest as a group with common characteristics (the lexical repetition and its meanings) and an idiosyncratic character, and, on the other hand, we have placed these instances among a larger inventory of types of clause combination with grammatical meanings. More specifically, in treating structures like $X[m] X, Y ; X$ kse- $X, Y$ and $X X, Y$ as constructions, we have assumed an evolutionary process from free syntax and language use to more restricted forms of expression. This process may hold for other types or strategies of asyndetic clause linkage (especially for subordination, see Cristofaro 2003).

Thus, an issue that arises (and which has been taken up, but, due to limitations of space, is not included in the current presentation) is whether 
the evolution towards constructions expressing a grammatical meaning can be considered a case of "grammaticalization across clauses" (Hopper \& Traugott 1993, 2003). Hopper \& Traugott (1993) have proposed three subsequent stages of grammaticalization of clause combination, based on a number of morphosyntactic, semantic and pragmatic criteria: parataxis > hypotaxis > subordination (Hopper \& Traugott 1993: 179). If the concessive constructions in question reflect instances of grammaticalization, where should they be placed along this cline of grammatical clause linkage?

In a similar vein, it remains to be seen whether the formal and structural differences between these three types of constructions (some of which have been mentioned in section 1 ) reflect differences in status with respect to the relevant levels of grammaticalization. There is, for example, evidence that the constructions involving echo-reduplication and repetition with kse-can be regarded as instances of hypotaxis, whereas the construction involving simple repetition is located at the stage of parataxis. This evidence, however, cannot be discussed in the current paper.

A final issue that may be worth mentioning is that, so far, we have been dealing with repetition of verbs, hence with "legitimate" cases of clause linkage; The question is what happens when $X$ (the repeated item in the above constructions) is not a verb, hence we cannot strictly talk about clauses, as, e.g., in jatros (kse) jatros, đio paketa tin imera kapnizi 'doctor (kse-)doctor, two packets the day smoke-3.SG.PR' "he may be a doctor, but he smokes two packets of cigarettes a day". In all likelihood, the first part of the concessive relation (jatros (kse)jatros), which is a case of repetition of a noun, must be treated separately from a model of grammaticalization that is based on criteria of "clause linkage". Such a treatment, however, would certainly require a separate and more extended study.

\section{List of Abbreviations}

$\begin{array}{ll}1 & 1^{\text {st }} \text { person } \\ 2 & 2^{\text {nd }} \text { person } \\ 3 & 3^{\text {rd }} \text { person } \\ \text { GEN } & \text { genitive } \\ \text { IMP } & \text { imperative } \\ \text { INTERJ } & \text { interjection } \\ \text { IPFV } & \text { imperfective } \\ \text { PL } & \text { plural } \\ \text { PR } & \text { present } \\ \text { PFV } & \text { perfective } \\ \text { PST } & \text { past } \\ \text { SG } & \text { singular }\end{array}$




\section{References}

Athanasiadou, A. 1997. Concession and adversativeness: areas of convergence and divergence. In B. Smieja and M. Tasch (eds.), Human contact through language and linguistics. Peter Lang, 3-16.

Couper-Kuhlen, E. and B. Kortmann. 2000. Cause, Condition, Concession, Contrast: Cognitive and Discourse Perspectives. Berlin: Mouton de Gruyter.

Couper-Kuhlen, E. and S. Thompson. 2000. Concessive Patterns in Conversation. In E. Couper-Kuhlen and B. Kortmann (eds.), Cause, Condition, Concession, Contrast: Cognitive and Discourse Perspectives. Berlin: Mouton de Gruyter, 381410.

Cristofaro, S. 2003. Subordination. Oxford: Oxford University Press.

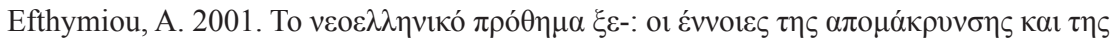
$\alpha \lambda \lambda \alpha \gamma \eta \dot{\zeta} \kappa \alpha \tau \alpha \dot{\sigma} \tau \alpha \sigma \eta$ s. [The Modern Greek prefix kse-: the notions of removal and change

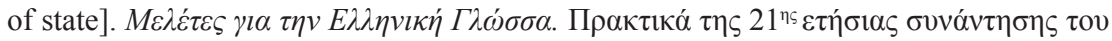

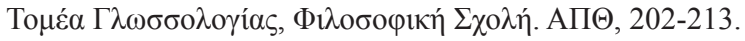

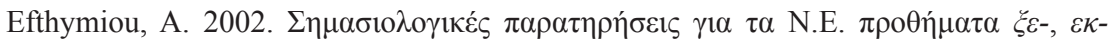
кal $\alpha \pi o_{-}$. [Semantic observations on the Modern Greek suffixes kse-, ek- and apo-].

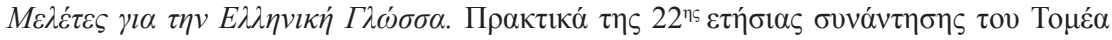

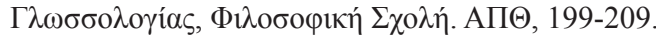

Fillmore, C.J., P. Kay and M.C. O'Connor. 1988. Regularity and Idiomaticity in Grammatical Constructions: The case of let alone. Language 64: 501-538.

Haiman, J. 1986. Constraints on the form and meaning of the protasis. In Traugott, E.C. (ed.), On conditionals. Cambridge: Cambridge University Press, 215-227. 
Halliday, M.A.K. and R. Hasan. 1976. Cohesion in English. London, New York: Longman.

Hopper, P. 1987. Emergent grammar. Berkeley Linguistic Society 13, 139-157.

Hopper, P. and E.C. Traugott. 1993. Grammaticalization. Cambridge: Cambridge University Press.

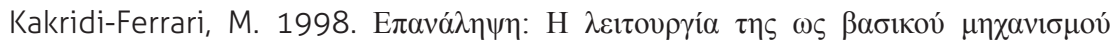
$\sigma \tau \eta \gamma \lambda \omega ́ \sigma \sigma \alpha$. [Repetition: its function as basic mechanism in language]. PhD dissertation. National and Kapodistrian University of Athens.

Kallergi, H. Kallergi (2013). Reduplication at the word level: the Greek facts in a typological perspective. PhD dissertation. Aristotle University of Thessaloniki.

Keane, E. 2005. Phrasal Reduplication and Dual Description. In B. Hurch (ed.), Studies on Reduplication. Berlin and New York: Mouton de Gruyter, 239-262.

Kirchner, J.S. 2010. Minimal Reduplication. PhD dissertation. University of California, Santa Cruz.

Kitis, E. 2002. On the Modern Greek conditional connective an or towards restoring the image of the Greek culture. In M. Makri-Tsilipakou (ed.), Selected Papers on Theoretical and Applied Linguistics. From the 14th International Symposium April, 2000. Thessaloniki: University Studio Press, 154-174.

König, E. 1988. Concessive Connectives and Concessive Sentences: Crosslinguistic Regularities and Pragmatic Principles. In J.A. Hawkins (ed.), Explaining Language Universals. Oxford, New York: Basil Blackwell Ltd., 145-166.

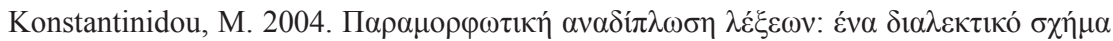
$\lambda$ ó

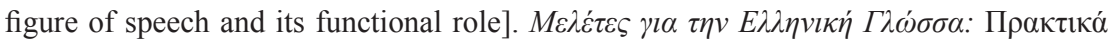

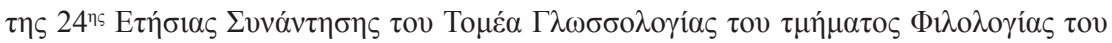

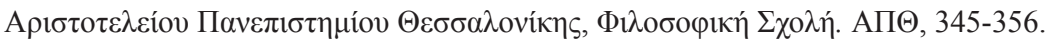

Latos, A. 2009. Concession on Different Levels of Linguistic Connection: Typology of Negated Causal Links. Retrieved 9 February 2012 from http://www.ncl.ac.uk/ linguistics/assets/documents/5Latos.pdf.

Moravcsik, E. 1978. Reduplicative Constructions. In J.H. Greenberg (ed.), Universals of Human Language, Vol III. Stanford: Stanford University Press, 297-334. 
Moravcsik, E. and M. Daniel. 2005. Associative Plural. In M. Haspelmath, M.S. Dryer, D. Gil and B. Comrie (eds.), The World atlas of Language Structures 1. New York: Oxford University Press, 150-154.

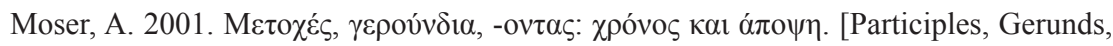

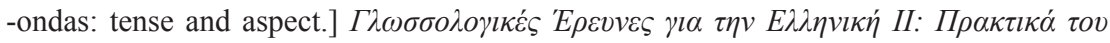

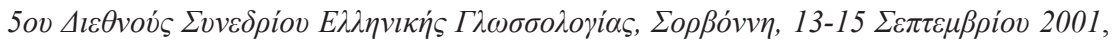
111-114.

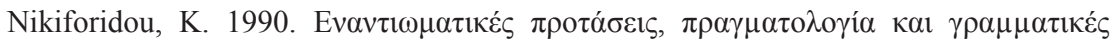

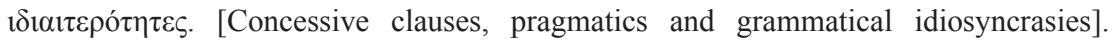

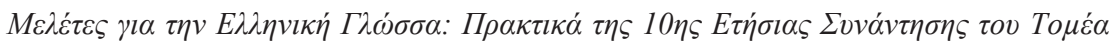

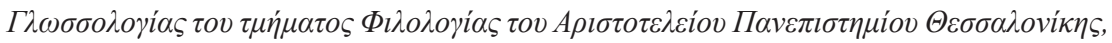

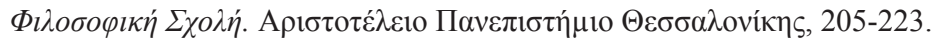

Rudolph, E. 1996. Contrast: Adversative and concessive relations and their expressions in English, German, Spanish, Portuguese on sentence and text level. Berlin and New York: Walter de Gruyter.

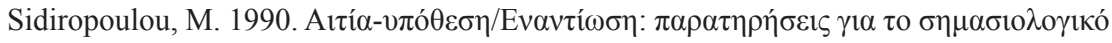

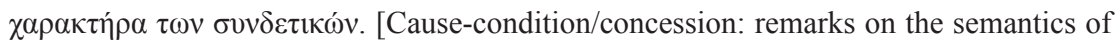

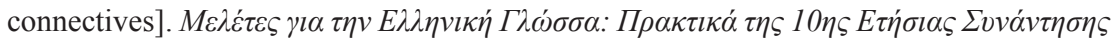

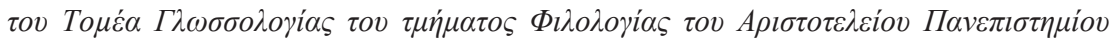

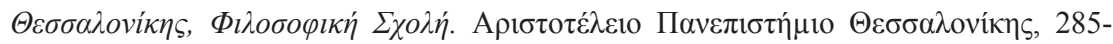
294.

Sperber, D. and D. Wilson. 1995. Relevance: Communication and Cognition. [Second Edition]. Oxford, Berlin: Blackwell.

Stolz, T., C. Stroh and A. Urdze. 2011. Total Reduplication: the Areal Linguistics of a Potential Universal. Studia Typologica 8. Berlin: Akademie Verlag.

Stolz, T. 2008. Total reduplication vs. echo-word formation in language contact situations. In P. Siemund, and N. Kintana (eds.), Language Contact and Contact Languages. Amsterdam, Philadelphia: John Benjamins B.V., 107-132.

Taylor, J.R. 2002. Cognitive Grammar. Oxford: Oxford University Press.

Tsimpli, I.M. 2000. Gerunds in Greek. Journal of Greek Linguistics 1, 133-169.

van der Auwera, J. and V.A. Plungian. 1998. Modality's Semantic Map. Linguistic Typology 2, 79-124. 
Major Trends in Theoretical and Applied Linguistics

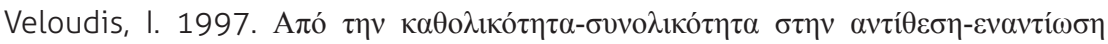
[From totality to contrast-concession]. Studies in Greek Linguistics 17, 417-423.

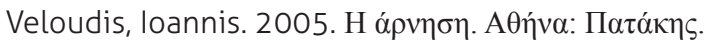

